\title{
Design and Simulation base study of single band microstrip patch antenna for GSM900, mobile communication.
}

\author{
Arshad Wahab, Xu Jiadong, Tariq Rahim \\ Department of Electronics and Information, Northwestern polytechnic University, 710129, Shaanxi, Xi'an, \\ China.
}

Abstract: The single band microstrip patch antenna having narrow operating bandwidth around the GSM900 band has been designed and simulated. Theoretical analysis and design has been performed by the Finite Difference Time Domain (FDTD) method based on the electromagnetic field solver Empire software. The proposed antenna achieved the desire operating bandwidth with relatively low profile, and suitable for mobile communication handsets.

\section{Introduction}

In this article, the design of the microstrip patch antenna has been explained. Then a compact microstrip patch antenna has been designed for use in cellular phones and simulations are performed. Finally, the results obtained from the simulations are discussed.

\section{Design specifications}

The design of rectangular microstrip patch antenna has based on three essential parameters.

(1) Frequency of Operation $\left(f_{r}\right)$ : The Global Systems for Mobile communications (GSM) uses the frequency range from $890-960 \mathrm{MHz}$.Hence the proposed antenna designed must be able to operate in $890-960 \mathrm{MHz}$ and the resonant frequency selected for this design is $930 \mathrm{MHz}$.

(2). Dielectric Constant of the substrate $\left(\boldsymbol{\varepsilon}_{\mathbf{r}}\right)$ : The dielectric constant of 4.4 has been used for this design. The use of the substrate having high dielectric constant can reduce the size of antenna.

(3).Height of dielectric substrate (h): The height of the substrate selected for the proposed antenna is $7 \mathrm{~mm}$.The antenna use for the cellular phones should be small, and compact in size. So the height selected is small. The parameters of the proposed antenna are: $\mathrm{f}_{\mathrm{r}}=0.93 \mathrm{GHz}, \boldsymbol{\varepsilon}_{\mathrm{r}}=4.4$, and $\mathrm{h}=7 \mathrm{~mm}$.

\section{Design Procedure:}

The width of the antenna is given by the equation (1).

$$
W=\frac{c}{2 f r} \sqrt{2 /\left(\varepsilon_{\mathrm{r}}+1\right)}
$$

Substituting $\mathrm{c}=3 \times 10^{8} \mathrm{~m} / \mathrm{s}, \mathrm{TM}_{\mathrm{r}}=4.4$ and $\mathrm{f}_{\mathrm{o}}=930 \mathrm{MHz}$ we get $\mathbf{W}=\mathbf{9 8 . 1 6} \mathbf{m m}$

The effective dielectric constant ( $\left.\mathrm{TM}_{\text {reff }}\right)$ has calculated using equation (2).

$$
\varepsilon_{\text {reff }}=\frac{\varepsilon r+1}{2}+\frac{\varepsilon r-1}{2}\left[1+12 \frac{h}{W}\right]^{-1 / 2}
$$

Substituting $\mathrm{TM}_{\mathrm{r}}=4.4, \mathrm{~W}=98.16 \mathrm{~mm}$ and $\mathrm{h}=7 \mathrm{~mm}$ we get $\mathbf{T} \mathbf{M}_{\text {reff }}=\mathbf{3 . 9 5}$.

The effective length $\mathrm{L}_{\mathrm{eff}}$ is given by the equation (3).

$$
\mathbf{L}_{\text {eff }}=\frac{\mathbf{c}}{2 \mathbf{f f}_{\mathbf{r} \sqrt{\varepsilon_{\mathbf{r}}}}}
$$

Substituting $\mathrm{TM}_{\text {reff }}=3.95 \mathrm{MHz}, \mathrm{c}=3 \times 10^{8} \mathrm{~m} / \mathrm{s}, \mathrm{f}_{0}=930 \mathrm{MHz}$, we get $\mathbf{L}_{\text {eff }}=\mathbf{8 1 . 2} \mathbf{m m}$.

The length extension $\Delta \mathrm{L}$ can be calculated using the equation (4).

$\Delta \mathrm{L}=0.4124 \mathrm{~h} \frac{\left\{\varepsilon_{\text {eff }+0.3\}\left\{\frac{W}{h}+0.264\right\}}\right.}{\left\{\varepsilon_{\text {eff }-0.258\}\left\{\frac{W}{h}+0.8\right\}}\right.}$

Substituting $\mathrm{TM}_{\text {reff }}=3.95, \mathrm{~W}=98.16 \mathrm{~mm}$, and $\mathrm{h}=7 \mathrm{~mm}$, we get, $\Delta \mathbf{L}=\mathbf{3 . 2 5 1} \mathbf{m m}$.

The actual length of the patch has been calculated by subtracting length extension from effective length as:

$$
\mathbf{L}=\mathbf{L}_{\text {eff }}-2 \Delta \mathbf{L}
$$

Substituting $\mathrm{L}_{\text {eff }}=81.2 \mathrm{~mm}$ and $\Delta \mathrm{L}=3.251 \mathrm{~mm}$, we get $\mathbf{L}=\mathbf{7 4 . 6 9 4 m m}$.

If the size of the ground plane is greater than the patch by almost six times the substrate thickness then similar result for finite and infinite ground plane will be obtained. The ground plane dimensions will be;

$\mathrm{L}_{\mathrm{g}}=6 \mathrm{~h}+\mathrm{L}=6 \times 7 \mathrm{~mm}+74.698 \mathrm{~mm}=116.698 \mathrm{~mm}$
$\mathrm{~W}_{\mathrm{g}}=6 \mathrm{~h}+\mathrm{W}=6 \times 7 \mathrm{~mm}+98.16 \mathrm{~mm}=140.16 \mathrm{~mm}$ 
A coaxial probe type feed has been used in the proposed design. The feed point must be at that point on the patch, where the input impedance is $50 \mathrm{ohms}$ for resonant frequency. The feed point location having the coordinates $\left(\mathrm{x}_{\mathrm{f}}, \mathrm{y}_{\mathrm{f}}\right)$, while center of the patch has been taken as the origin. In order to have the dimensions of the propose antenna small to be practically applied in cellular phones, the radiating patch to the antenna's ground plane need to be short circuit with a shorting pin. The modified top patch design to achieve the $900 \mathrm{MHz}$ operation shown in the figure 1.

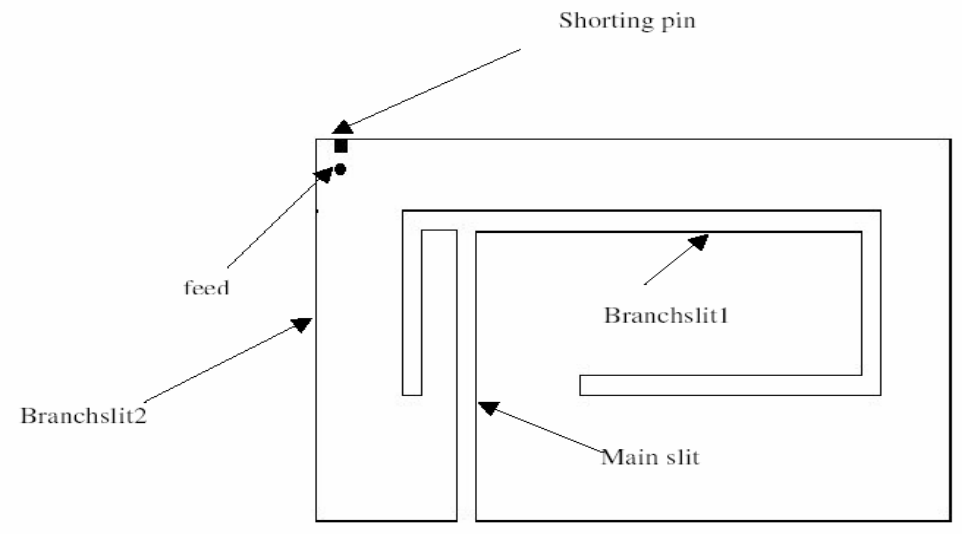

.Figure 1: Geometry of the proposed antenna.

Simulation setup and Results: The software Finite Difference Time Domain (FDTD) method based field solver EMPIRE by IMST GmbH EMPIRE is a full electromagnetic simulator in which two Maxwell's curl equations are discretized in space and time [9]. Which has been used to model and simulate the microstrip patch antenna. A Gaussian pulse voltage with unit amplitude, as;

$$
\mathrm{V}(\mathrm{t})=\exp \left[-(\mathrm{t}-\mathrm{to})^{2} / \mathrm{T}^{2}\right]
$$

Where $\mathrm{T}$ is the period and $\mathrm{t}_{\mathrm{o}}$ be the center time, has been used to excite in the probe feed. The current and voltage are transformed to Fourier domain after final time domain results are obtained. The input impedance of the antenna is obtained from the equation (9).

$$
\mathrm{Z}_{\text {in }}=\mathrm{V}(\mathrm{f}) / \mathrm{I}(\mathrm{f})
$$

The input impedance is then used to get the return loss characteristics of the proposed antenna. After this the operating bandwidths is calculated. For the radiation pattern characteristics, a sinusoidal excitation at the probe feed is used and given by;

$$
\mathrm{V}(\mathrm{t})=\sin \left(2 \pi \mathrm{f}_{\mathrm{r}} \mathrm{t}\right)
$$

Where $f_{r}$ is the resonant frequency. The field distribution has been taken at one instant of time after the steady state has been reached. The radiation pattern has been calculated by using the near field to far-field transformation. Figure 2, shows the voltage waveforms at the input terminals of the antenna.

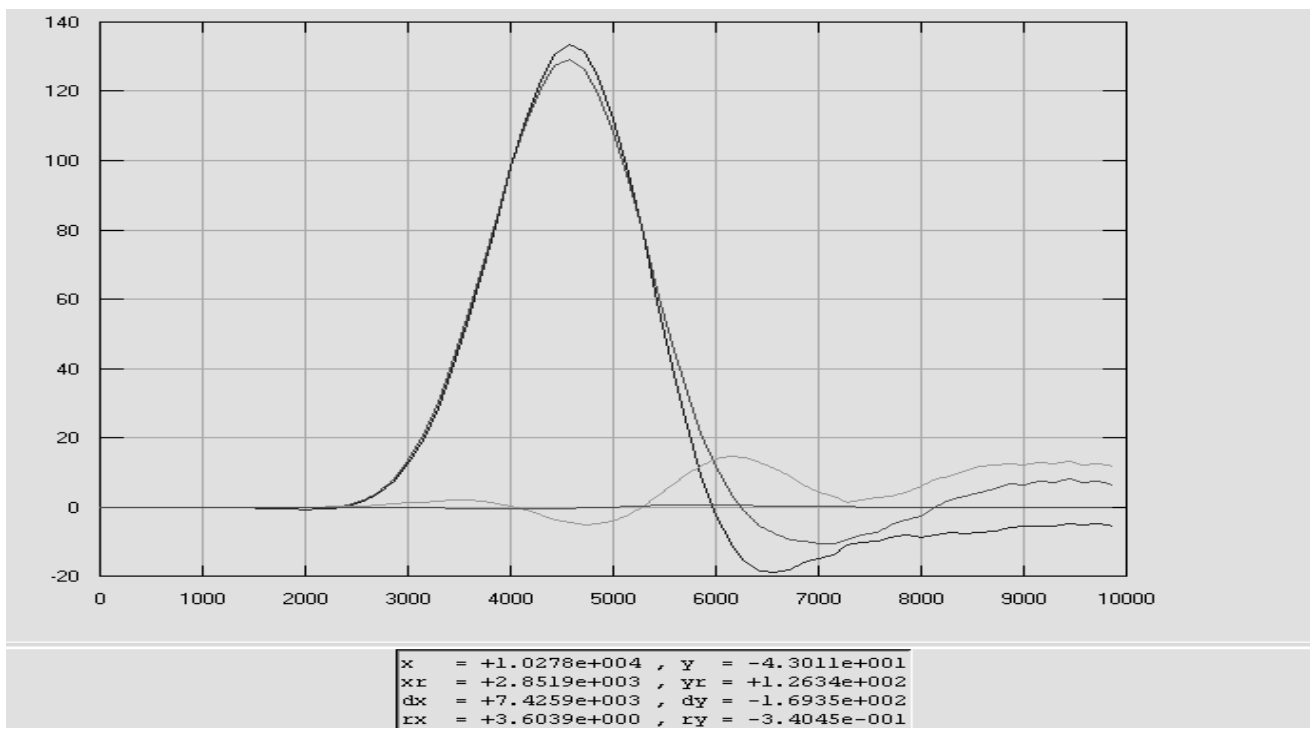

(a) 


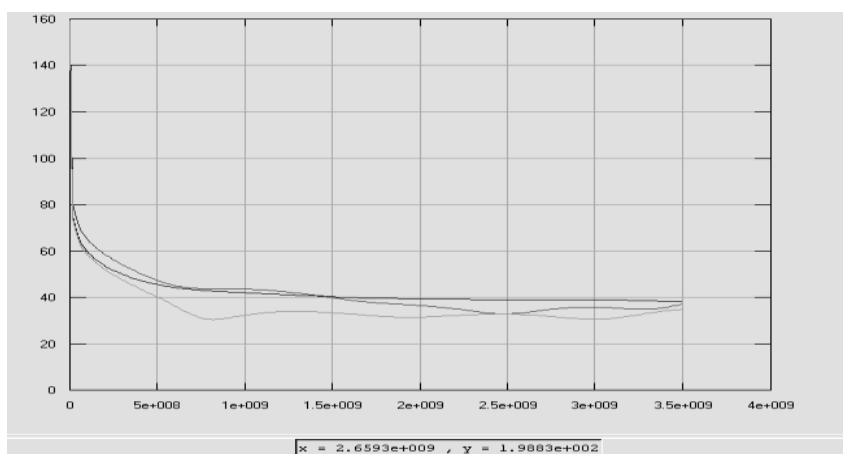

(b)

Figure 2: Voltage waveform at the input terminal of antenna (a) as a function of time (b) as function of frequency.

At the operating frequency the reflected voltage amplitude has small and the incident voltage amplitude is high over a range of time steps, it is clear that much of the energy is radiated in to the space rather than reflected back. This can be taken as a good justification that the antenna functions well at the designed frequency.

The coaxial probe feed having radius of $0.4 \mathrm{~mm}$. The bandwidth of the antenna is those range of frequencies in which the return loss is greater than 7.3-db, which is equivalent to 2.5:1VSWR.The bandwidth of the designed antenna for this feed point location is $45-\mathrm{MHz}$ and the center frequency is $830-\mathrm{MHz}$, which is closed to the desired frequency of operation.

\section{Return loss plot}

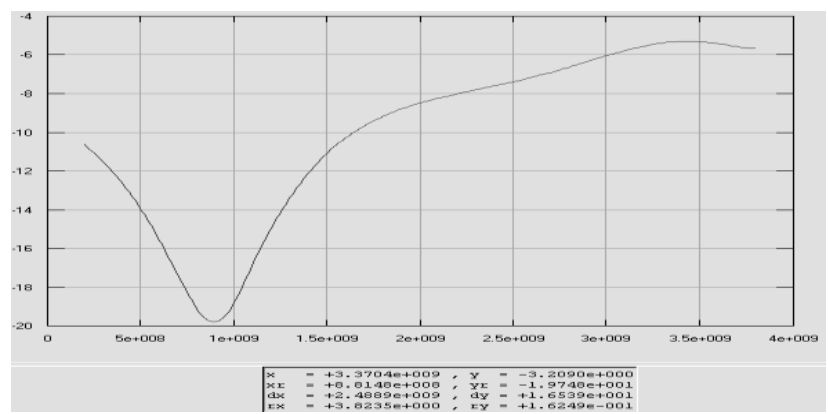

Figure 3: Return Loss for Feed at the edge of the patch

The volume of the proposed antenna has smaller volume of $30 \times 10 \times 7 \mathrm{~mm}^{3}$, and the simulated bandwidth is not large enough to meet the bandwidth requirement of the GSM band. Further improvement in the impedance bandwidth is needed to obtain optimal performance of the GSM mobile phones.

\section{Input Impedance}

The figure 4 shows the simulation output for the input impedance, the peak of the real part of the impedance does not occur exactly at the resonant frequency of the antenna, this is due to the presence of the feed reactance.

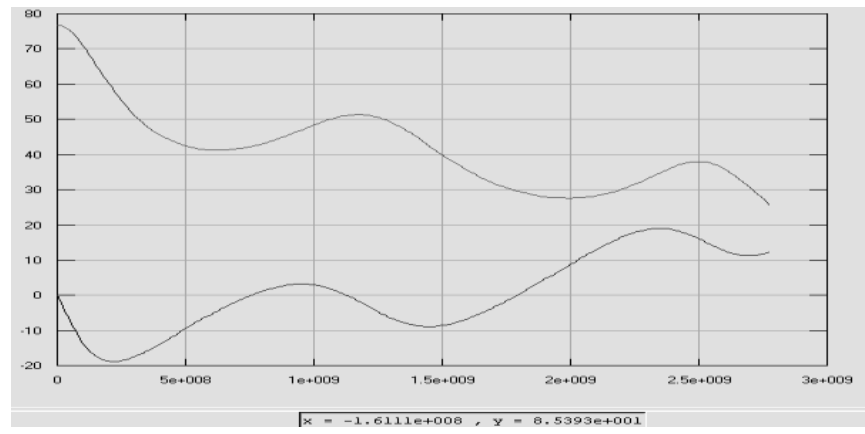

Figure 4: Input Impedance of the antenna. 


\section{Radiation Pattern Plots}

The figure.5, illustrates the 2D radiation pattern of the antenna at the desired frequency for $\phi=0^{\circ}$ and $\phi=90^{\circ}$. The microstrip patch antenna radiates normal to the patch surface. The elevation pattern is important for $\phi=0^{\circ}$ and $\phi=90^{\circ}$.

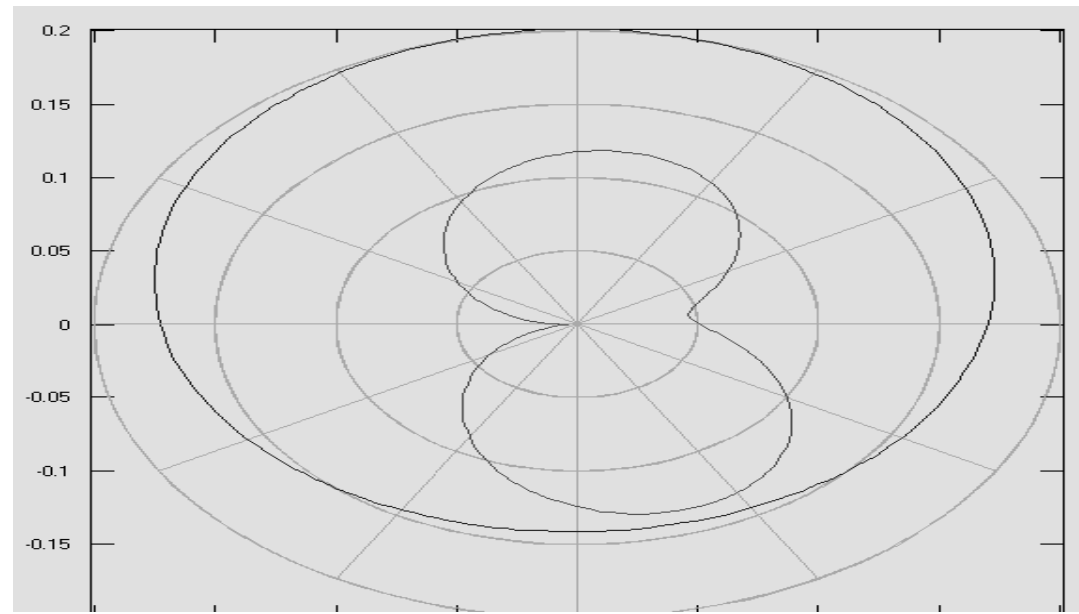

Figure 5: 2D Radiation Pattern Plots (Elevation pattern for $\phi=0^{\circ}$ and $\phi=90^{\circ}$ ).

Figure.6 shows the three dimensional radiation pattern of the simulated antenna for GSM900 band. The maximum gain has been obtained in the broad side direction.

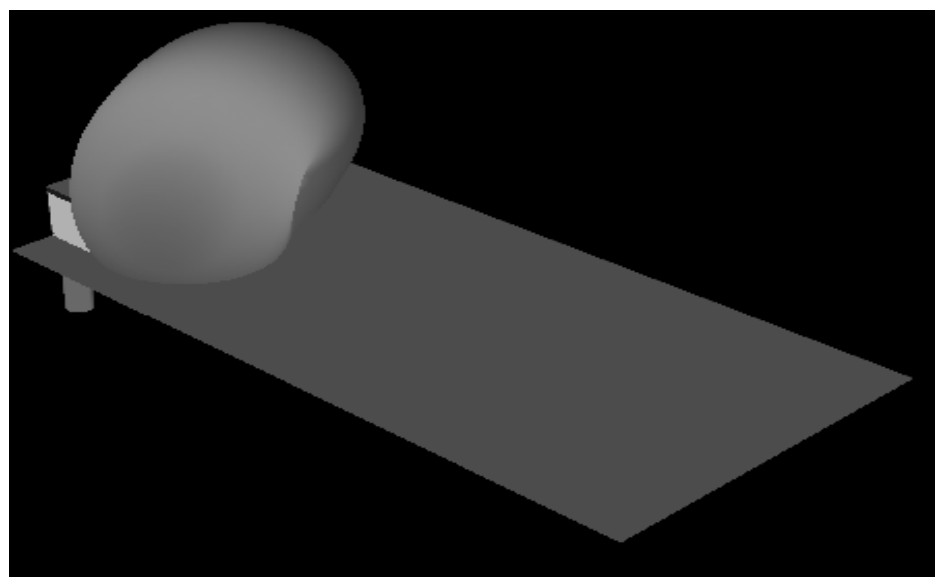

Figure 6: 3D Radiation Pattern of the antenna for the GSM900 band.

\section{Conclusion and Remarks}

The simulation results clearly exhibit that the antenna radiates mostly on the patch side and radiates small amount on the back side. The planner antenna has the advantage over the conventional whip antenna, which have omnidirectional radiation. This help to eliminate the possible electromagnetic energy absorption by the users head. The simulation results show that the antenna radiates well at the operating frequency.

\section{References}

[1.] Constantine A. Balanis, Antenna theory analysis and design, 2nd edition, John Wiley \&sons, Inc, 1997.

[2.] David M.Pozar, Microwave Engineering, 3rd edition, Wiley international edition, 2005.

[3.] Johm D.Kraus, Antennas, 2nd edition,McGaraw-Hill Company,1988.

[4.] Roger F.Harrington,Time Harmonic Electromagnetic Fields, McGraw-Hill Company, 1961.

[5.] Warren L.Stutzman, Gary A.Thiele, Antenna Theory and Design,2nd edition, John Wiley \&sons, Inc,1998.

[6.] Robert E.Collin, Antennas and Radio Wave Propagation, McGraw-Hill, Inc, 1985.

[7.] Jean-Francois Zurcher and Fred E.Gardiol, Broadband Patch Antenna, Artech House, Boston, 1995.

[8.] Kin-Lu Wong, Planar Antennas for Wireless Communications, Wileyinterscience, 2005.

[9.] EMPIRE User and Reference Manual, IMST GmbH, 2004. 